\title{
The Concept and Practice of Creativity Workshop for Engineering and Technology Education in Universities of Technology
}

\author{
Jen Chia Chang and Pei Jou Chiu
}

\begin{abstract}
Engineering and technology education is an important element contributing to national development, socioeconomics, and talent nurturing progress, while creative thinking is even considered one of the most important abilities required of present and future talents in engineering and design fields. In this study, targeting teachers and students of institutes of higher education in Taiwan, the " 2015 Creativity Workshop for Future Engineers" course was conducted. In addition, through creative skills, technology commercialization, and creative teaching (teacher group), creative projects (student group), and other topic learning and exchanges, a survey on learner satisfaction was carried out. Findings show high overall learner satisfaction, especially the environment that consistently gained recognition. As for lecturer performance, the teachers showed higher satisfaction than the students. In the course, the teachers demonstrated keener learning compared to the students. Hence, it is suggested that teachers be adopted as targeted in related future course contents in order to enhance their creative ability and knowledge. Furthermore, the course content will be developed into a framework of engineering and technology education related topic courses, which shall serve as a reference for course design. It is hoped that teaching and learning will head towards the direction of creativity and innovation.
\end{abstract}

Index Terms-Creativity, engineering and technology education, project work, workshop.

\section{INTRODUCTION}

In recent years, in order to foster engineering and technology talents and enhance scientific and technological advancement, the National Science Council applied science education, specifically the inclusion of "curriculum innovation, teaching innovation, learning strategy, innovation evaluation, evaluation, and accreditation of engineering education" in 2009 as the research project solicitation focus in order to enhance the country's capacity for engineering and technology education research, thus indicating the significance of engineering and technology education as far as national economic development is concerned. Creativity does derive from nowhere. The purpose of creative teaching is to combine the professional skills and creative thinking of students, put knowledge to good uses, and elicit creativity under the guidance of

Manuscript received August 1, 2015; revised October 20, 2015. This work was supported in part by the Ministry of Science and Technology (MOST 103-2511-S-027-004-MY3).

The authors are with the Graduate Institute of Technological and Vocational Education, National Taipei University of Technology, Box 4037 No.1, Sec. 3, Zhongxiao E. Rd., Taipei City, 10608, Taiwan (e-mail: jc5839@ntut.edu.tw,pjal00024@mail.ntut.edu.tw). professional specialist faculty, with hopes of creating more tangible and intangible products, contributing positively to mankind, and bringing more convenience and services in daily life

\section{LITERATURE REVIEW}

\section{A. Creative Engineering Education}

Engineering is defined as the creative application of science [1]. To improve environmental problems, we should develop new manufacturing systems and products, generate and manage energy, and design and implement transportation, new communication systems, and health care instruments. However, the development factors of the engineering community include sufficiency, quality, productivity, creativity and innovation, and other key factors [2]. The job of engineers is not just production, manufacture, construction, organization, and development, engineers are also in charge of project executions, covering manpower, machines, material use and allocation [3]. They exert a certain degree of influence on modern technology, while creativity marks the beginning of national competitiveness and industrial and economic development [2]. Therefore, the most industries could expect from engineers hired is creativity [1], in order to explore and scrutinize available data or information [4], all of which are intended to satisfy human needs, maintain the safety of lives, and expanding the economic development of a country.

Ref. [5] took into consideration unlikelihood from the original creation and resolved the problem of applicability and proposed the creativity of engineering products with the following characteristics:

1) Effectiveness: the product solves the problem.

2) Novelty: the product is surprising.

3) Elegance: the product is beautiful or pleasing.

4) Generalizability: the product is broadly applicable.

Obviously, in view of the physical objects and energy within engineers' work scope and in living applications, engineers that produce innovative products through creativity contribute to improved human living functions, flourishing development of enterprises, and overall national progress.

However, how what distinguishes creative, creativity, and innovation? Based on the interpretation of [6], [7], creativity includes bringing into full play creativity intelligence and the display of innovation results. According to the definition of [1], creativity requires both originality and effectiveness-originality, which are novel and valuable in use. 
It originated to help people resolve problems. It helps break deadlocks based on intuition and create opportunities for links and identification [7] defines creativity as the ability to implement new ideas, restructuring engineering in the pursuit of challenge and high sensitivity to improve existing product related problems; innovation is the search of breakthroughs from the original and implemented in the directions of novelty, change, refinement, and differentiation. The Ministry of Education has also set creativity as an education effectiveness indicator.

All in all, creative thinking and innovation technology are products of creativity implementation, representing the level of creativity expression; innovation is to subvert the past output through the generation of tangible and intangible products. In this study, creativity was adopted as the basis for exploring student development in creativity.

It takes coaching and nurturing to engage in creative engineering learning [2], [4], while students and economic developments are aspects covered in creative engineering education [8]. However, since engineering instructors lack practical experience, they often fail to lead students towards comprehension and citations of examples. Additionally, professors from research-oriented universities are mostly engaged in research in the engineering discipline, but overlook practical and application aspects. Therefore, practices ought to be the focus of teaching, so as to foster outstanding engineers [3].

Ref. [9] proposed four factors to consider when targeting engineering education development:

1) Take into account different operations throughout the evolution of engineering.

2) Focus on basic engineering practices.

3) Take into consideration humanities and social sciences, as human actions contribute to engineering development.

4) Take localized social, economic, and political factors into consideration.

Creativity can be taught and learned through formal university classes, as well as seminars and workshops [2], [4] described fostering student creativity as helping students to understand their potential and giving prospective graduates the confidence to achieve social development in the future.

Teaching methods such as individual training, motivation training, competition-based training, professionalism-based creative tasks, etc. may be adopted to implement teaching through work modes provisioned or new interactive models. Student organizations and groups will attempt to be co-writers of new ideas or the so-called creators, thus achieving a creative atmosphere and elicit the internal motivation of students [8]. Teachers can also provide students with examples of problems or solutions in order to identify and eliminate negative thinking, further promote and foster student creativity, ignite the hope of creativity, and cope with real problems that possibly arise in the future as well as professional engineering related stress [4].

In short, engineering requires creativity, and students' creativity while attending school should be emphasized. Teachers, teaching, and environment also affect the development of student potential and the understanding of practical engineering situations. Secondly, students' motivation will elicit their active learning and search of solutions. Thus, changes and design of teaching methods supplied by teachers should take student and social needs into account in order to better foster desirable engineering talents in the future.

\section{B. Project Work}

According to the study of [10], [11], topic practice can help students integrate theoretical knowledge and skills learned, thus cultivating teamwork, interactive thinking, problem analysis, and creative problem solving abilities through cooperation with others. Students will then be able to bring into full play their abilities once they enter the workplace, which will help them quickly adapt to the environment [11].

Topic practice related courses include: creative thinking teaching, imparting to students ways to resolve problems, and creative thinking strategies, which are applied in creative product design practices [10]. The purpose of innovation in industries can be grasped, and peoples' living needs can be catered to [4], [12]. For instance, social needs or problems, new product plans or trends, personal or organizational development opportunities, and special projects (such as teachers' research projects or industry-academia cooperation) are all items to focus on [4]. As mentioned in the research, during the topic process, teachers do the following: 1) supervise student progress; 2) assist students in problem solving [13]; and 3) teach students to identity correct creative thinking [4]. Students are responsible for the following: 1) to collect industry related information, devise small-scale projects, and improve self-learning achievement [13]; and 2) integrate groups with diverse backgrounds and establish learning targets through cooperation [4]. The course contributes to the following: 1) "learn by doing" under simulated situations to subtly enhance students' creativity; 2) When learning results are obtained, their interest in the field of engineering is enhanced [13]; and 3) enhance students' interest in the engineering field when learning outcome is achieved [12].

\section{Creative Project Work Activities}

Topic courses begin in the general and vocational high school stage; they are regarded as a way to foster students' practical ability, especially in engineering. In this study, relevant general and vocational high school and college curriculum planning serve as a reference for workshop conduction.

1) 2008 "creative design and invention patent teaching" seminar

Introduction: The innovation and creativity center of Far East University has been established for teachers and industries in Taiwan. The purpose of the 12-hour seminar is to enable teachers to learn creativity, design, invention, and patent related skill, while fostering creative literacy and eliciting students' learning motivation and enhancing learning effectiveness through teaching [14].

Content:

a) Theory and Application of Creative Design Methods

b) Creative Inventions and Commercialization

c) Inventions Create My Life 
d) The Secret to Successful Inventions.

e) From Innovative Invention to Patent Application Filing.

f) Is this Your Invention? How to Help Researchers Complete Inventions

g) How to Enhance Students' Creative Thinking Ability

h) Creative Thinking Teaching Experience Sharing

2) 2010 a dialogue on creative teaching between industry and academia

Introduction: The Instructional Resources Center of Vocational and Technological College and University in the Northern District are headed by the teachers of vocational high schools and include high schools in the Northern District. The purpose of the 8-hour seminar is to facilitate the mutual benchmark study between the industry and academia, thus achieving the common goal of growth [15].

Content:

a) Teaching Applications of Social Media

b) Alternatives of Creative Ideas

c) Case Sharing by Teachers

d) Case Sharing of Creative Cuisine Ideas

e) Case Sharing of Teaching Applications of Mental Map

f) The New Paradigm of Creating

3) 2011 "create, creative, innovation" seed teacher training and production seminar

Introduction: The Department of Management Information Systems and Graduate Institute of Information Technology and Management of Takming University of Science and Technology is conducted by general and vocational high school teachers and students. The purpose of the 5-day and 40-hour seminar activity is, first of all, to foster students' creativity use in order to enhance their professional abilities in the future workplace. Secondly, it is intended to promote students' understanding of patent R\&D, commercialization processes, and creative product marketing, thereby serving as a reference for further studies in the future. Thirdly, it guides students through the patent application and commercialization process, from practical creation to innovation skills. Lastly, it assists students in combining creative contents and developing technical transfers through outstanding work. [16].

\section{Content:}

a) Creative Opportunities and Sources

b) Six Innovative Thinking Hats and Mental Map Practice

c) Innovative Market Assessment Analysis and Marketing $7 \mathrm{P}$

d) Product Creative Thinking Methods and Group Discussions

e) Vendor Visits

f) Understanding and Application of Intellectual Property and Technical Transfer Commercialization

g) Patent Application Development

h) Innovative Plan Writing

i) Creative Work Competition

4) 2013 "teacher creativity training camp and practice" seminar

Introduction: The Teacher education center of China Medical University and Asia University is conducted by the teachers of the school. The purpose of the 2-hour seminar is for teachers to enhance teaching diversity and work efficiency through various innovative strategies, thereby elicit students' creativity and satisfying their learning needs.

Content: The 12 Keys and 8 Strategic Techniques of Creative Teaching Training; Case Analysis and Effective Use of Creative Teaching Training [17].

\section{5) 2013 NUU creative seminar}

Introduction: A series of courses (16 lessons) were commenced by the National United University(NUU). The purpose of the seminar is for students to gain an insight into creativity around you. From "learning by doing" students undergo training to develop the ability to discover and solve problems [18].

Content:
a) The Creativity of "Earning 12 Million in Six Months"
b) A Little Creativity Does Magic
c) Opportunities and Risks of Creativity
d) Creativity Is Around You
e) The Conceptualization and Implementation of Creativity
f) The Wisdom of Creative Time and Life Management
g) Creativity and Patents
h) Creativity Competition Work Display and Judging
i) Creativity and Fashion
j) Creativity and Culture

\section{6) 2014 creativity seminar}

Introduction: National United University is handled by general and vocational high school teachers and students. The purpose of the 19-lesson course is to lead participants to pay attention to the habit of inconveniences in life, thereby eliciting their imagination, and creativity and providing those opportunities to engage in problem-solving practice [19].

\section{Content:}

a) Creativity Is Around You

b) Acquiring Creative Inspiration from Nature

c) Creativity Contest for Finals

d) Creativity and Intellectual Property Rights

e) Creativity and Fashion

f) Creativity and Invention

g) Common Creative Skills

h) TRIZ - Systematic Pure Creative Thinking Method

i) Creativity Leading to the Light-The True Meaning of "Invention"

j) Creativity Contest and Awarding Ceremony

\section{7) 2014 creative project course, creative patents, and commercialization seminar}

Introduction: The Department of Mechatronic Engineering of National Taiwan Normal University was conducted by vocational high school teachers. First, the purpose of the 6-hour seminar is to provide teachers and students who have achieved outstanding performance in topic production an opportunity to display their work, thus eliciting their potential in career development. Second, it is intended to improve teachers and students' understanding of and respect for intellectual property rights, enhance the patent related ability and knowledge of teachers and students, assist in assessing the commercialization of award-winning topic production works, and deepen the practical value of topic production courses [20]. 


\section{Content:}

a) Creativity and Invention- A View of Brain Assets based on Creative Ideas

b) Is Creativity a Must in Topic Production Courses?

c) Creative Design Commercialization- Practical Sharing

\section{8) 2014 innovation patent, commercialization, and} creative production course teaching seminar

Introduction: The K-12 Education Administration of Ministry of Education was conducted by vocational high school teachers and students. The three purposes of the 6-hour seminar were to: 1 . provide a reference for the Center for the Study Area of Business Administration when conducting topic production teacher seminars, thereby strengthening the ability and knowledge of topic courses; 2 . discuss topic production teaching examples and featured practices of vocational high schools to facilitate promotion in schools; 3. deepen teachers' teaching ability and knowledge, thus promoting the professional development of teachers [21].

Content:

a) A Dialogue with Sparkles- Topic Production Taught by Environment

b) Innovative Application of Topic Production Feature Course Models

c) Sharing of Practical Topic Production Execution Methods

d) Experience Sharing of Creativity and

Application-oriented Topic Production

Based on the creative project courses, the framework of the majority of the courses was compiled in this study. It covers descriptions of creativity sources and techniques, creativity elicitation and use training, samples of patency and commercialization, project work and practice competitions, case sharing of creative products, etc. For some of the courses, vendor visits are scheduled. The purpose of the course is to provide cultivate students' creativity through teachings imparted by teachers. Students, through participation in practical production (such as topic production), can enhance their confidence in their own creativity.

\section{METHOD}

\section{A. Research Design}

This study targets the teachers and students of colleges and universities in Taiwan, a total of 17 schools and 45 student participants.

Based on literature review, this study compiled creativity related course sand drafted the activity content. The validity was established through the expert review board. The activity design is described below [22].

Name: 2015 Creativity Workshop for Future Engineers

Hours: 8 hours

\section{Content:}

1) The only way to creativity: The Promotion of Problem-Solving Strategies: 5W1H method, brainstorming, KJ method, group example method, mental map, cause analysis, example method, and so on.
2) The concept and examples of technology commercialization: Operational processes (description of innovation and operation), management (description of patents), and launch of technical commercialization process (case sharing of enterprises).

3) Creativity learned from experts (student group): Experience and case sharing of innovation and inventions.

4) Creative projects (student group): Description of creativity elicitation, product innovation steps, and discussion of examples.

5) Creative teaching (teacher group): Focuses of creative project courses, differential analysis of competition inventions and product inventions, government and private assistance paths towards inventions, and trends of innovative inventions in recent years.

6) Creative teaching practice (teacher group): Descriptions of design connotation, elicitation of creative thinking, flip teaching of topic practice courses.

The satisfaction questionnaire design in this study is in reference to the after-school questionnaire survey of the Extended Education Training Center of Fo Guang University Data processing [23], which was edited into the "2015 Creativity Workshop for Future Engineers' learner satisfaction questionnaire" research tool. The questionnaire content consists of four parts: lecturer performance, environment, course, and basic information. The scales, based on the 5-point Likert scale design, are highly satisfied, satisfied, average, dissatisfied, and highly dissatisfied, with scores ranging from 5 to 1 .

\section{B. Data Processing}

Since the content analysis is used to classify and tally contents using systematic and quantitative methods and carry out narrative explanation, specific topics are selected for appropriate sampling and analysis [24]. The analysis of creative project courses in this study contains the list of five items, namely, organizers, participants, number of hours, purposes, and activity contents, which are compared for differences. The activity content frequency was analyzed and results were presented.

After recovering and archiving the questionnaires, the SPSS was used for the descriptive analysis of background variable frequency distribution and percentages the one sample t-test was adopted to analyze the mean values, standard deviations, and performance of the respective satisfaction questions. According to the research of [25], the mean value $(\bar{x})$ identified using the 5 -point Likert Scales is a continuous variable: $1 \leq \bar{x}<1.5$ is "highly dissatisfied", $1.5 \leq \bar{x}$ $<2.5$ is "dissatisfied", $2.5 \leq \bar{x}<3.5$ is "average", $3.5 \leq \bar{x}<4.5$ is "satisfied", and $4.5 \leq \bar{x} \leq 5$ is "highly dissatisfied", which are the dimensions of the satisfaction sequence. In reference to the research method of [26], the mean values of the satisfaction questions for the two groups (teacher group and student group) were marked, while the bisect of "highly satisfied" $(\bar{x} \geq 4.5)$ was drawn to explore the trend of the satisfaction in different questions for the two groups. Independent samples t-test was conducted to explore whether or not significant differences existed in terms of the learner satisfaction of the teachers and students. 


\section{Discussion}

\section{A. The Analysis of Participant Basic Information}

This part covers frequency distribution and percentages to describe the distribution of participants' background information (Table I).

TABLE I: ONE-SAMPLE T-TEST ANALYSIS

\begin{tabular}{|c|c|c|c|c|c|}
\hline Title & M & SD & t-test is 4.5 & $\mathrm{t}$-test is 5 & Sequence \\
\hline Lecturer performance & 4.58 & 0.59 & .892 & $-4.459 *$ & 3 \\
\hline Professional & 4.9 & 0.29 & $6.167^{*}$ & -1.451 & \\
\hline Practicability & 4.71 & 0.64 & 1.526 & $-2.034 *$ & \\
\hline Timing & 4.38 & 0.59 & -.925 & $-4.812 *$ & \\
\hline Interactive & 4.33 & 0.58 & -1.323 & $-5.292 *$ & \\
\hline $\begin{array}{l}\text { Service, environment, } \\
\& \text { equipment }\end{array}$ & 4.75 & 0.6 & $2.772 *$ & -1.706 & 1 \\
\hline Administration & 4.81 & 0.51 & $3.740 *$ & $-3.670 *$ & \\
\hline Attitude & 4.9 & 0.3 & $6.167 *$ & -1.451 & \\
\hline Meal & 4.71 & 0.46 & $2.121 *$ & $-2.828 *$ & \\
\hline Convenience & 4.71 & 0.9 & 1.088 & -1.451 & \\
\hline Equipment & 4.62 & 0.67 & .815 & $-2.609 *$ & \\
\hline Course & 4.73 & 0.54 & $2.398 *$ & $-3.247 *$ & 2 \\
\hline Fix & 4.81 & 0.51 & $2.772 *$ & -1.706 & \\
\hline Understand & 4.67 & 0.58 & 1.323 & $-2.646^{*}$ & \\
\hline Application & 4.71 & 0.56 & $1.752 *$ & $-2.335^{*}$ & \\
\hline Overall & 4.69 & 0.58 & $2.703^{*}$ & $-4.393 *$ & - \\
\hline
\end{tabular}

Served/enrolled school: Out of the 17 schools in total, 9 were from the St. John's University, accounting for $20 \%$; 9 were from the Ling Tung University, accounting for $20 \%, 5$ were from the National Changhua University of Education, accounting for $11.1 \%, 3$ were from Hwa Hsia University of Technology, accounting for $6.7 \%$; six institutions each had two, namely, National Taipei University of Technology, the National Yunlin University of Science and Technology, the Chang Gung University, the China University of Technology, the Tainan University of Technology, and the De Ling Institute of Technology, accounting for $4.4 \%$ respectively; and 6 institutions each had one, namely, the National Taichung University of Science and Technology, the National Chinyi University of Technology, the Taipei Chengshih University of Science \& Technology, the Vanung University, the Yuanpei University, the Overseas Chinese University, and the Tungfang Design Institute, each accounting for $2.2 \%$ respectively.

Served/enrolled departments: Out of the 18 departments, there were 10 visual communication design departments, accounting for $22.2 \%, 7$ creative design departments, accounting for $15.6 \%, 5$ each of industrial education and technology departments and electronic engineering departments, accounting for $11.1 \%, 3$ cosmetics application management departments, accounting for $6.7 \%, 2$ each of industrial design departments and product design departments, accounting for $4.4 \%$, and 1 for each of the 11 departments, namely, industrial engineering and management department, creative life design department, interior design department, creative product design department, information engineering department, information management department, computer and communication engineering department, digital multimedia design department, digital technology design department, mechanical and computer aided engineering department, and institute of electrical integration, accounting for $2.2 \%$ respectively.

Job titles: Out of the 45 people in total, 17(37.8\%) were teachers and 28(62.2\%) were students.

\section{B. The Analysis of Participant Satisfaction Performance}

The mean values and standard deviations of learner satisfaction are as shown in Table 1 . In this study, $4.5 \leq \bar{x} \leq 5$ "high level" was adopted as the $\mathrm{p}$ value to test the significance. With the overall mean of 4.69 and the standard deviation of 0.58 , the high level t-test reached significant standard $(t=-4.393, p<.05)$, indicating the students' high level of overall satisfaction. The mean values of the lecturer performance questions were between 4.33 and 4.9 , while the standard deviations were between 0.29 and 0.64 , indicating the high level t-test reached a significant level $(t=-4.459$, $p<.05)$; the mean values of service, environment, and equipment were between 4.62 and 4.9 , while the standard deviations were between 0.3 and 0.9 , indicating the tendency of the high level t-test reaching significant standard $(t=-1.7$, $p<.05)$; the mean values of course questions were between 4.67 and 4.81 , while the standard deviations were between 0.51 and 0.58 , indicating high level t-test reaching significant standard $(t=-3.247, p<.05)$; the dimension ranked from high to low sequence are: service, environment, $\&$ equipment $(\bar{x}$ $=4.75)$, course $(\bar{x}=4.73)$, and lecturer performance $(\bar{x}=4.58)$.

\section{The Differential Analysis of Learner Satisfaction}

Fig. 1 shows the trend diagram of the satisfaction mean values of the teacher and student groups in the questions. The questions show that both group were highly satisfied $\bar{x} \geq 4.5$ satisfaction), showing the overall satisfaction (A) was all higher than 4.5. In particular, the teachers had higher satisfaction than the students, inclining towards the upper left of the highly satisfied bisect, except convenience (S4) where the students showed higher satisfaction. The questions in the lecturer performance dimension showed less consistent viewpoints, as the marks were dispersed. As for timing (L3), interactive (L4) was relatively lower, while professional (L1) satisfaction was relatively higher; the satisfaction of both groups in the questions under service, environment, and equipment dimensions were inclined towards the bisect, indicating consistency of both groups that were highly satisfied. The teachers' views towards attitude (S2) were higher than the students; the questions under the course learning effectives dimension were more concentrated: The teachers 'satisfaction scores were between 4.6 and 5, while the students' scores were between 4.5-4.7.

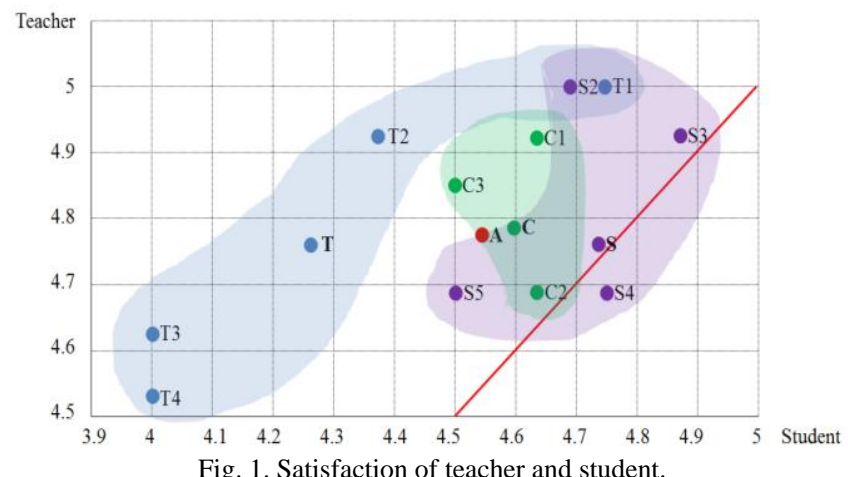
Fig. 1. Satisfaction of teacher and student. 
TABLE II: THE DIFFERENTIAL ANALYSIS OF TEACHERS AND STUDENTS IN TERMS OF SATISFACTION

\begin{tabular}{|c|c|c|c|c|c|}
\hline Title & Job title & Amount & $\mathrm{M}$ & SD & t value \\
\hline $\begin{array}{l}\text { Course learning } \\
\text { effectiveness }\end{array}$ & $\begin{array}{l}\text { Teacher } \\
\text { Student }\end{array}$ & $\begin{array}{l}17 \\
28\end{array}$ & $\begin{array}{l}4.77 \\
4.28\end{array}$ & $\begin{array}{l}0.24 \\
0.51\end{array}$ & $5.156^{*}$ \\
\hline $\begin{array}{l}\text { Service, } \\
\text { environment, \& } \\
\text { facilities }\end{array}$ & $\begin{array}{l}\text { Teacher } \\
\text { Student }\end{array}$ & $\begin{array}{l}17 \\
28\end{array}$ & $\begin{array}{l}4.77 \\
4.73\end{array}$ & $\begin{array}{l}0.28 \\
0.37\end{array}$ & .77 \\
\hline $\begin{array}{l}\text { Course learning } \\
\text { effectiveness }\end{array}$ & $\begin{array}{l}\text { Teacher } \\
\text { Student }\end{array}$ & $\begin{array}{l}17 \\
28 \\
\end{array}$ & $\begin{array}{l}4.79 \\
4.60 \\
\end{array}$ & $\begin{array}{l}0.27 \\
0.57\end{array}$ & 1.113 \\
\hline Overall & $\begin{array}{l}\text { Teacher } \\
\text { Student }\end{array}$ & $\begin{array}{l}17 \\
28\end{array}$ & $\begin{array}{l}4.78 \\
4.54\end{array}$ & $\begin{array}{l}0.23 \\
0.41\end{array}$ & 1.386 \\
\hline
\end{tabular}

The independent samples t-test was adopted in this study, targeting differences of job titles in terms of satisfaction in three dimensions, namely, "lecturer performance", "service, environment, and facilities", and "course learning effectiveness" and overall analysis (Table II the differential analysis of teachers and students in terms of satisfaction). Among them, "lecturer performance" showed a significant difference $(t=5.156, \quad p<.05)$, and the teachers were significantly higher than the students.

\section{CONCLUSION AND SUGGESTIONS}

\section{A. Conclusion}

The name of the course study conducted in this study was the 2015 Creativity Workshop for Future Engineers. In this 8-hour course, taught different means of creativity (including creative skills), including: the concept and example of technology commercialization, learning creativity from experts (student group), creative project (student group), creative teaching (teacher group), creative teaching practice (teacher group), and other content. In the second half, teaching was imparted to the teacher group and student group in different venues.

As for the background of participants, St. John University and Ling Tung University comprised the majority. In particular, the students' participation rate was higher than that of the teachers. The satisfaction levels of the three dimensions ranked from high to low are: service, environment, and equipment, course learning effectiveness, and lecturer performance. The participants of different job titled varied in their opinion towards satisfaction. The results mostly showed the professors had higher satisfaction. Compared to the questions under lecturer performance, the questions under course learning effectiveness showed better consistency compared to the questions on teachers' overall performance, while both sides were inclined towards highly satisfied in the service, environment, and equipment questions. Specifically, the teachers' satisfaction in lecturer performance was higher than that of the students.

\section{B. Suggestions}

The original course design was intended to provide time for participants to practice. However, due to time and budget considerations, practical work failed to be provided. Moreover, the morning session of the activity was mostly lectures. Like traditional narrative teaching, it is suggested that agendas be conducted for more than two days to better meet activity needs and enable participants to engage in interactive discussion and generate more creative thinking.

From the activity, it was found that the overall satisfaction was relatively higher, especially services, environment, and equipment provided that gained high recognition. It is suggested that in future conduction of relevant activities, this part of the activity be handled more carefully, as the "preconceived" views can lead to participants' higher overall satisfaction. The teachers showed higher scores than the students in lecturer performance, and they were more diligent in learning and asking questions. It is presumed that the teachers may have had negligence in creative project course arrangements. The activity provided them recommendations or guide to help them clarify their learning or improvement direction. Hence, it is suggested that teachers be targeted in relevant future activities in order to enhance their ability and knowledge.

The activity themes planned in the 2015 Creativity Workshop for Future Engineers were compiled and summarized to form the topic practice course framework, including six themes: innovative problem analysis and problem solving, creative skills, creativity conceptualization and sources, product design and development, technology commercialization, topic practice and competition, taking into account life problems, solidification of creativity, product commercialization, topic practice experience, and other development. They are expected to serve as a reference for professors when planning college/university topic practice courses. Through practical experience, students' creativity and confidence will be cultivated to make full preparation before stepping into the workplace.

\section{REFERENCES}

[1] Z. Tekic, A. Tekic, and V. Todorovic. (February 2015). Modelling a laboratory for ideas as a new tool for fostering engineering creativity. Procedia Engineering. [Online]. Available: http://www.sciencedirect.com/science/article/pii/S1877705815004117

[2] I. Badran, "Innovation? Are they different? Do we need both?" European Journal of Engineering Education, vol. 32, no. 5, pp. 573-585, 2007.

[3] C. Yih-Young. (June 2008). Engineering education and engineer incubation. Chinese Culture University Hwa Kang Journal of Engineering. [Online]. Available: http://ir.lib.pccu.edu.tw/handle/987654321/21919

[4] Z. Liu and D. J. Shönwette. (January 2004). Teaching creativity in engineering. International Journal of Engineering Education. [Online]. Available: http://www.ijee.ie/articles/Vol20-5/IJEE1511.pdf

[5] D. H. Cropley and A. J. Cropley, "Engineering creativity: A systems concept of functional creativity," in Creativity Across Domains: Faces of the Muse, J. C. Kaufman and J. Baer, Eds. New Jersey: Lawrence Erlbaum Associates Inc, 2005, ch. 10 , p. 176

[6] Ministry of Education. (March 2003). White paper on creative education- Establishing a republic of creativity (R.O.C.) for Taiwan. [Online]. Available: http://www.edu.tw/userfiles/url/20120920154709/92.03\%E5\%89\%B5 \%Е9\%80\%A0\%Е5\%8А\%9B\%Е6\%95\%99\%Е8\%82\%В2\%Е7\%99\% BD\%E7\%9A\%AE\%E6\%9B\%B8.pdf

[7] C. Y. Lin, C. J. Wu, T. C. Chen, and K. T. Lu, "Concept and enhancement strategy of creativity," Taipei County Education, vol. 70, no. 11-15, 2000.

[8] R. M. Felder, D. R. Woods, J. E. Stice, and A. Rugarcia. (2000). The future of engineering education II. Teaching methods that work. Chemical Engineering Education. [Online]. Available: http://www4.ncsu.edu/unity/lockers/users/f/felder/public/Papers/Quart et5.pdf

[9] J. Trevelyan, "Towards a theoretical framework for engineering practice," in Engineering Practice in a Global Context, B. Williams, J. Figuerido, and J. Trevelyan, Eds. Leiden: CRC Press/Balkema, 2014, pp. 35-36. 
[10] H. C. Hsiao, J. C. Chang, C. Y. Huang. (2000). The influence of cooperative learning on the creativity of undergraduate project work. Chinese Journal of Science Education. [Online]. Available: http://www.cheme.utm.my/chem/news\%20events/future\%20engineeri ng/future\%20eng2.pdf

[11] J. L. Tsai, "A study of developing an implementation mechanism of practical projects for a selected vocational high school," M.S. thesis. National Yunlin University of Science and Technology, Yunlin, China, 2000.

[12] J. L. Tang and M. F. Huang. (September 2007). Correspondences between the special project courses in the universities and the need of industries: A study case in the field of mechanics. Journal of Educational Practice and Research. [Online]. Available: http://academic.ntue.edu.tw/ezfiles/7/1007/img/41/20-2-6.pdf

[13] C. Terkowsky and T. Haertel. (2015). On learning objectives and learning aktivities to foster creativity in the engineering lab. [Online]. Available:

http://ieeexplore.ieee.org/xpl/articleDetails.jsp?arnumber=7017864\&p unumber\%3D7002490\%26sortType\%3Dasc_p_Sequence\%26filter\% 3DAND(p_IS_Number\%3A7017737)\%26pageNumber\%3D5

[14] Far East University. (December 2008). 2008 Creative Design and Invention Patent Teaching Seminar. [Online]. Available: http://icc.feu.edu.tw/

[15] National Taipei University of Technology. (March 2010). 2010 a dialogue on creative teaching between industry and academia. [Online] Available:

http://wwwged.web.ntut.edu.tw/ezfiles/18/1018/img/801/286440743. doc

[16] Takming University of Science and Technology. (March 2012). 2011 "Create, Creative, Innovation" Seed Teacher Training and Topic Production Seminar. [Online]. Available: http://www.tnu.edu.tw/rec/tnu5834/ti/3/100/100-8.pdf

[17] China Medical University. (September 2013). 2013 Teacher Creativity Training Camp and Practice Seminar. [Online]. Available: http://cmu4c.cmu.edu.tw/2013/news/detail.php?id=616

[18] National United University. (September 2013). 2013 NUU Creative Seminar. [Online]. Available: http://www.nuu.edu.tw/ UIPWeb/wSite/public/Attachment/f1378700167773.pdf

[19] National United University. (March 2015). 2014 Creativity Seminar. [Online]. Available: http://www.tzmarea.edu.tw/?p=4099

[20] National Taiwan Normal University. (November 2014). 2014 Creative Project Course, Creative Patents, and Commercialization Seminar. [Online]. Available: http://vtedu.mt.ntnu.edu.tw/vtedu/node/248

[21] Ministry of Education. (October 2014). 2014 Topic and Creative Production Course Teaching Seminar. [Online]. Available: http://vtedu.mt.ntnu.edu.tw/vtedu/node/245

[22] Technology Innovation and Creativity Research Room of National Taipei University. (March 2015). 2015 Creativity Workshop for Future Engineers. [Online]. Available: http://tcwffe.wix.com/workshop

[23] Fo Guang University. (2015). After-school questionnaire survey. [Online]. Available: http://industrial.fgu.edu.tw/files/archive/62 471b7be6.doc

[24] E. Babbie, The practice of social research, 9th ed. CA: Wadsworth, 2001.

[25] J. C. Chang, The Relationship of Organizational Innovative Climate and Performance of Innovative Management- Take Vocational High School As an Example, pp. 151-152. Taipei, R.O.C.: PRO-ED, 2005.

[26] S. López-Querol, S. Sánchez-Cambronero, A. Rivas, and M Garmendia. (June 2015). Improving civil engineering education: Transportation geotechnics taught through project-based learning methodologies. Journal of Professional Issues Engineering Education and Practice. [Online]. Available: http://ascelibrary.org/doi/abs/10.1061/(ASCE)EI.1943-5541.0000212

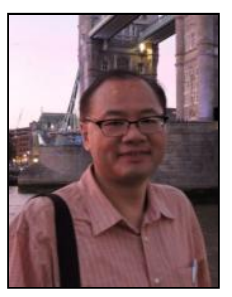

management.

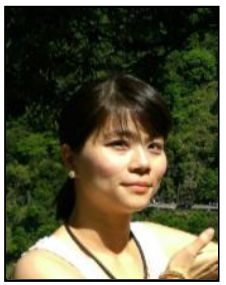

planning.
Jen Chia Chang is a professor with Graduate Institute of Technological and Vocational Education, National Taipei University of Technology in Taiwan. $\mathrm{He}$ received his Ph.D. degree in the Department of Industrial Education and Technology from National Changhua University of Education. His field of work is teaching and research on innovation strategy and management for school, human resource management $\&$ development, and organizational behavior and

Chiu Pei Jou is a project assistant with Graduate Institute of Technological and Vocational Education, National Taipei University of Technology. She received her master degree in Graduate Institute of Technological and Vocational Education from National Taipei University of Technology. Her research field is focused on creative thinking for course, information management, database management and maintenance, and enterprise resource 